\title{
Finite element analysis of three-layer concrete beam with composite reinforcement
}

\author{
Dinh Tho Vu ${ }^{1,2, *}$, Elena Korol $^{1}$, Yuliya Kustikova ${ }^{1}$, Huy Hoang Nguyen ${ }^{1}$ \\ ${ }^{1}$ Moscow State University of Civil Engineering, Yaroslavskoe Shosse, 26, Moscow, 129337, Russia \\ ${ }^{2}$ University of Transport Technology, Thanh Xuân, Ha Noi, Viet Nam
}

\begin{abstract}
Reinforced concrete structures play an increasing important role in civil and industrial construction, along with the technology of new concrete materials and their calculation theories. In order to improve the crack resistance of three-layer reinforced concrete (3L-RC) beams with the middle layer of lightweight concrete (LWC) material, the method of using polymer bars in place of steel bars is applied. In this study, the behavior of 3L-RC beams with steel bars and glass fiber reinforced polymer (GFRP) bars is simulated and analyzed by ANSYS software (base on the finite element analysis). The simulation of reinforced concrete (RC) beam work on computer software is a modern method, which allows to input many mechanical, physical properties of materials and geometric parameters of $3 \mathrm{~L}-\mathrm{RC}$ beams. The results of the samples beam analysis showed that the cracking resistance of 3L-RC beams with GFRP bars have been enhanced more than twice compared to 3L-RC beams with steel bars. Numerical modeling allows comparison between the obtained results and building theoretical dependences in a wide range of specified parameters in sectional construction of multilayer reinforced concrete elements. This would limit the number of actual test samples, increase the efficiency of experiments.
\end{abstract}

\section{Introduction}

At present, three-layer reinforced concrete structures with a middle layer of lightweight concrete (LWC) are used widely in the construction of civil buildings. Their appliances are: floor, roof slabs and covering structures of buildings in order to ensure the capability to withstand loads and insulation requirements for buildings [1, 2, 3, 4]. LWC of middle layer of three-layer beams is concrete with low average density, strength and low thermal conductivity (as polystyrenbeton). They occupy a central position between conventional RC structures and the mixed composite section with outlying layers of $\mathrm{RC}$ and the central layer of different types of thermal insulation materials, characterized by low strength and high deformation $[5,6,7]$. In the publications $[1,6,8]$, the theory and experimentation, calculating the three-layer structure with the middle layer from low thermal conductivity material polystyrenbeton, are presented. The results of previous studies $[1,10,11]$ show that cracks do not appear in multilayer reinforced concrete structures until the structure is

\footnotetext{
* Corresponding author: vuthoks@gmail.com
} 
elastic and the tension in the stretched zone reaches the ultimate tensile resistance, while the ratio of stresses and strains is subject to Hooke's law.

There are a number of studies on the repair and reinforcement of RC structures with composite components of carbon plastic, fiberglass [12 - 14]. These analyses have shown the advantages of carbon fiber in usage to reinforce RC beams. They increase cracking resistance and the load-bearing capacity of the RC beam.

This paper displays the usage of GFRP bars to increase the cracking resistance of multilayer reinforced concrete structure.

\section{Finite element model and research materials}

The study was carried out on three - layer RC beam samples with a size of 160x $2400 \times 250$ $\mathrm{mm}$ (B1 and B2). Structure of the beam samples: internal layer from low thermal conductivity polystyrenbeton with thickness $150 \mathrm{~mm}$, prismatic strength of concrete $\mathrm{R}_{\mathrm{b}}=$ 1.15 MPa, initial elastic modulus $\mathrm{E}=950 \mathrm{MPa}$ and external layer with thickness $50 \mathrm{~mm}$, prismatic strength of concrete $\mathrm{R}_{\mathrm{b}}=21.5 \mathrm{MPa}$, initial elastic modulus $\mathrm{E}=12000 \mathrm{MPa}$. The parameters of the concrete material used are shown in figure 1 and $1[1,2,4,9]$.

Table 1. Parameters of finite elements and characteristics of concrete in structural layers.

\begin{tabular}{lccc}
\hline Structure of the layers & External (1) & Interior & External (2) \\
\hline Thickness of layer, $\mathrm{m}$ & 0.05 & 0.150 & 0.05 \\
Prismatic strength of concrete $\mathrm{R}_{\mathrm{b}}, \mathrm{MPa}$ & 21.5 & 1.1 & 21.5 \\
Strength of concrete for tensile strength $\mathrm{R}_{\mathrm{bt}}, \mathrm{MPa}$ & 1.7 & 0.28 & 1.7 \\
Initial modulus of elasticity E, MPa & 12000 & 950 & 12000 \\
The Poisson's ratio $v=0.00189\left|R_{b}\right|+0.12$ & 0.16 & 0.122 & 0.16 \\
Average density of concrete $\rho_{\mathrm{b}}, \mathrm{kg} / \mathrm{m}^{3}$ & 1800 & 440 & 1800 \\
\hline
\end{tabular}

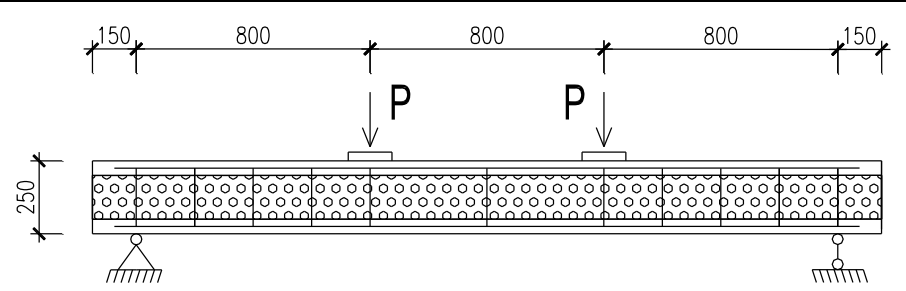

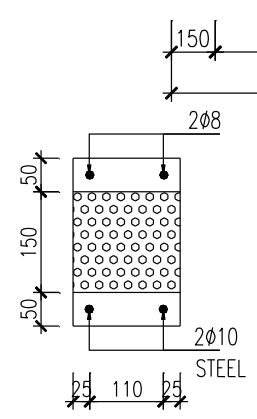

B1

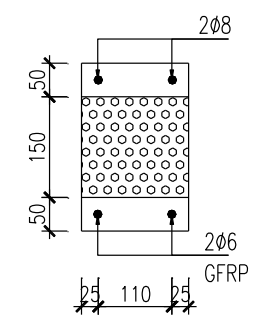

B2

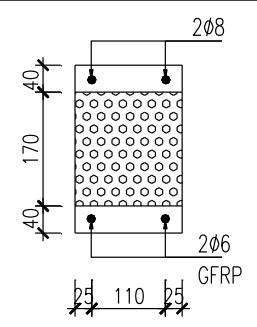

B3

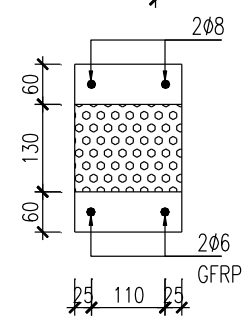

B4

Fig. 1. Parameters of the experimental model. 
For the steel beam, the young modulus, yield stress, ultimate strain and stress at ultimate are $200000 \mathrm{MPa}, 352 \mathrm{MPa}, 0.1085$ and $454.3 \mathrm{MPa}$. The GFRP bars have ultimate tensile strength of $900 \mathrm{MPa}$, an ultimate tensile strain of $0.022[15,17]$ and Young modulus of 30 $\mathrm{GPa}$.

Multilayer reinforced concrete test beams are simulated on ANSYS v18 software. Program ANSYS approves the input of geometric features of the cross-sector and parameters of steel bars, GFRP bars and concrete.

The Solid65 element involves linear isotropic and multi-linear isotropic components additional to the concrete material defined in ANSYS to properly model the concrete (Wolanski, 2004) $[18,20]$. The compressive uniaxial stress-strain curve for the concrete model is obtained by applying the equations (1) to (4) to the multi-linear isotropic stressstrain curve showed in figure number 2 (MacGregor, 1992) [19].

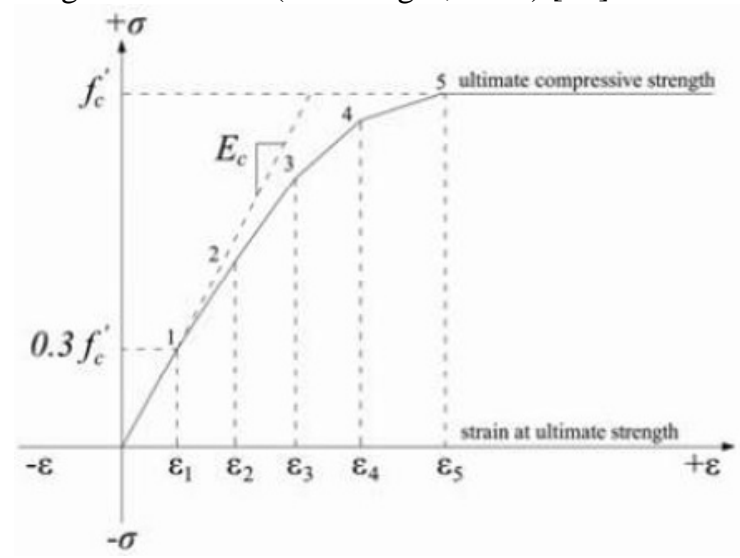

Fig. 2. Simplified compressive stress-strain curve for concrete (MacGregor, 1992).

Where $\varepsilon_{1}, \mathrm{f}_{\mathrm{c}}, \varepsilon$ và $\varepsilon_{0}$ are strain at the limit of the linear part $\mathrm{f}_{\mathrm{c}}=0,3 \mathrm{f}_{\mathrm{c}}$, concrete compressive stress, strain at stress $f_{c}$, and strain at the ultimate strength of concrete, respectively

$$
\begin{array}{r}
f_{c}=\varepsilon E_{c} \quad \text { if } \quad 0 \leq \varepsilon \leq \varepsilon_{1} \\
f_{c}=\frac{\varepsilon E_{c}}{1+\left(\frac{\varepsilon}{\varepsilon_{0}}\right)^{2}} \quad \text { if } \quad \varepsilon_{1} \leq \varepsilon \leq \varepsilon_{0} \\
f_{c}=f_{c}^{\prime} \quad \text { if } \quad \varepsilon_{0} \leq \varepsilon \leq \varepsilon_{u} \\
\varepsilon_{0}=\frac{2 f_{c}^{\prime}}{E_{c}}
\end{array}
$$

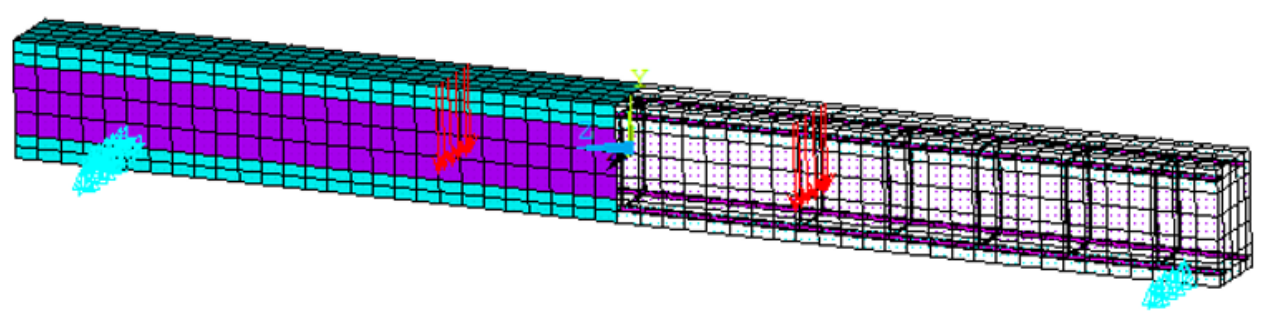

Fig. 3. Finite element model with the display of boundary conditions and loads. 
The LINK180 [20] was used to simulate steel, GFRP rebars and the stirrups. A bilinear relationship was used to represent the stress-strain curve of the steel reinforcement while a linear elastic behavior was used for the GFRP rebars.

A typical figure of the three-dimensional finite element mesh of the studied beams is shown in figure 3.

In authors' publications [1, 3, 6, 8, 9] the design scheme of distribution of forces and deformations in $3 \mathrm{~L}-\mathrm{RC}$ section with monolithic connection of layers is given in figure 4.
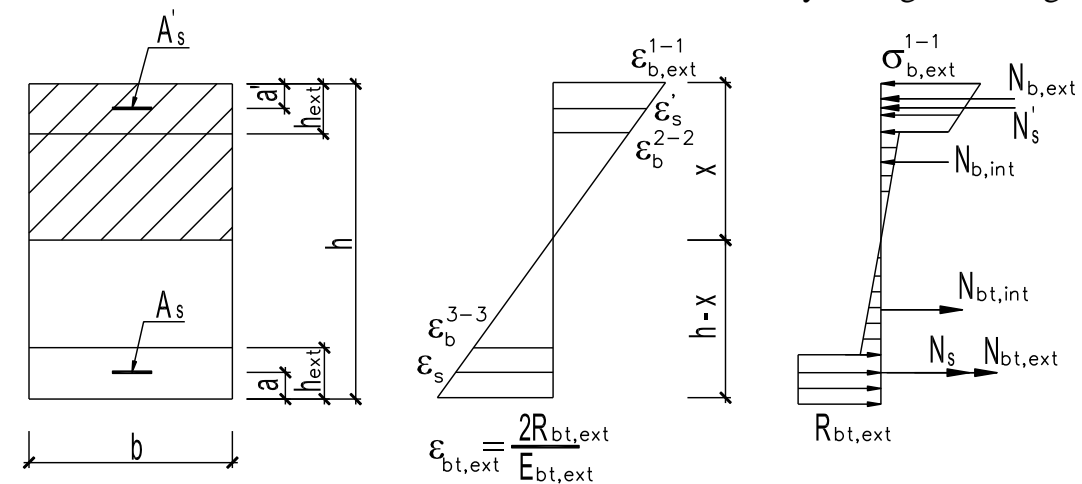

Fig. 4. Calculating schemes of distribution of forces and deformations in three-layer sections at elastic deformations of concrete of the middle layer in the compressed zones.

In the future, the calculation would be conducted for conventional reinforced concrete elements to cracks formation $[1,8]$.

$$
\sigma_{b t} \leq \gamma_{b t} \cdot R_{b t}
$$

$\sigma_{\mathrm{bt}}$ - principal tensile stresses;

$\mathrm{R}_{\mathrm{bt}}$ - resistance of concrete to axial tension;

$\gamma_{b t}$ - coefficient of concrete working conditions, with mesured influence of bi-axial complex stress condition "compression-tension" on the fortitude of concrete.

The deflection of three-layer structures from the bend corresponds to the bending of the beam, and the deflection from the shift is followed with a shift of the filler. In this case, there is a deflection of the cross-section with an additional curvature of the external layers.

The deflection from bending in mid-span of beam specimens to cracking is calculated according to the formula:

$$
f_{M}=\frac{M}{\varphi_{b 1} E_{b} J_{r e d}} \rho_{m} l^{2}
$$

The deflection from the transverse forces in any section of the beam element with the coordinate $\mathrm{x}$ is determined by the formula:

$$
f_{Q}=\int \frac{k Q(x)}{G F} d x+C_{Q}
$$

$\mathrm{C}_{\mathrm{Q}}$ - integration constant equal to zero at the hinge support of the beam;

$\mathrm{G}$ - shear modulus of material;

$\mathrm{k}$ - the coefficient that takes into account the shape and dimensions of the cross-section, the values of which are determined by the formula:

$$
k=\frac{F}{J^{2}} \int \frac{S^{2}(z)}{b(z)} d z
$$

$\mathrm{F}$ and $\mathrm{J}$ - the area and moment of inertia of the reduced section, respectively; 
$\mathrm{S}$ and $\mathrm{b}$ - the static moment and the width of the cut-off part of the reduced section, respectively.

\section{Results and discussion}

The analytical outcome of the 3L- RC beam using two steel bars (diameter 10mm) is shown in figure 5 .
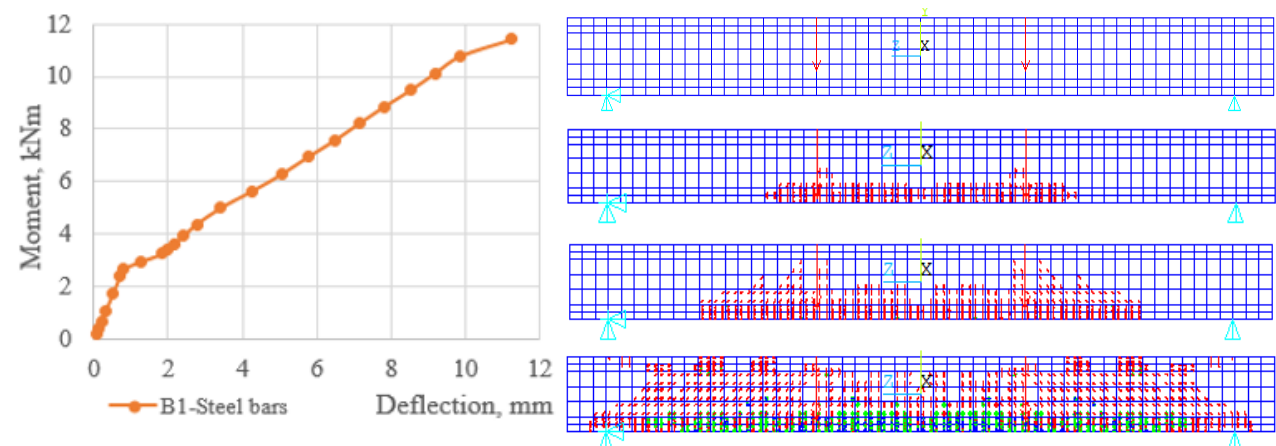

Fig. 5. Moment-deflection curve and crack pattern for B1.

According to the results from the model in ANSYS, when $\mathrm{M}_{\mathrm{crc}}=2.96 \mathrm{kNm}$ (deflection $\mathrm{f}=1,18 \mathrm{~mm}$ ), cracks begin to form and the value of the moment of crack formation according to the scheme figure $3 \mathrm{M}_{\mathrm{crc}}=3.22 \mathrm{kNm}$ (deflection $\mathrm{f}=1.25 \mathrm{~mm}$ ) when comparing the calculation results in ANSYS with theoretical results (scheme figure 3), the difference between the moments of crack formation was $8.8 \%$.

The analysis results of the $3 \mathrm{~L}-\mathrm{RC}$ beam using two GFRP bars (diameter $6 \mathrm{~mm}$ ) are shown in figure 6.
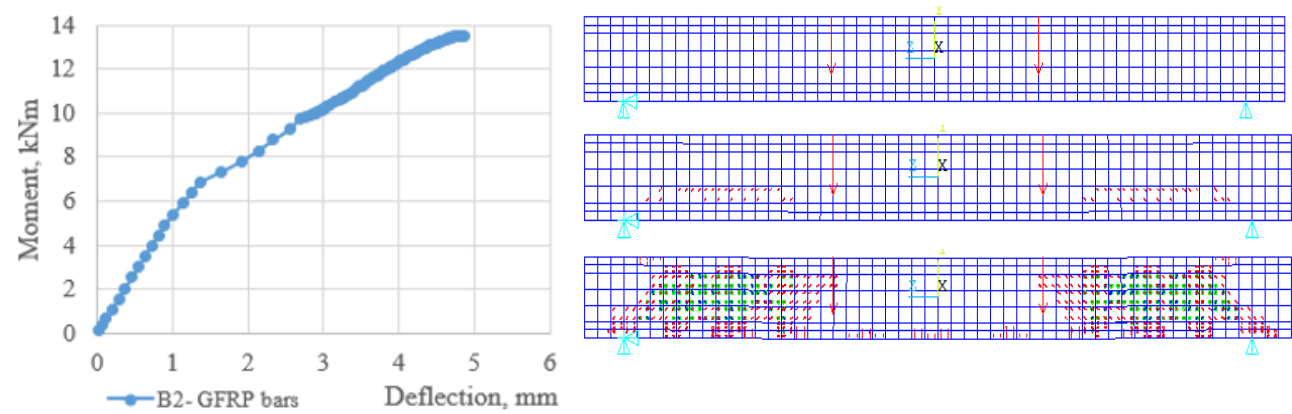

Fig. 6. Moment-deflection curve and crack model for B2.

With three-layer RC beam using two GFRP bars, when $\mathrm{M}_{\mathrm{crc}}=6.86 \mathrm{kNm}$ (deflection $\mathrm{f}=$ $1.33 \mathrm{~mm}$ ), cracks begin to form in the internal layer beam, and $\mathrm{M}_{\mathrm{crc}}=8.77 \mathrm{kNm}$ (deflection $\mathrm{f}=2.34 \mathrm{~mm}$ ), cracks begin to form in the external layer beam.

In this experiment, on three-layer reinforced concrete beams with GFRP bars (beam B2) cracks begin to appear in the internal layer and destroy in the shear section of the beams, but with beam B1, the first crack begins to appear in the external layer. Accordingly, composite bars change the stress-deformation state of three-layer reinforced concrete and redistribute internal force in the beam. 


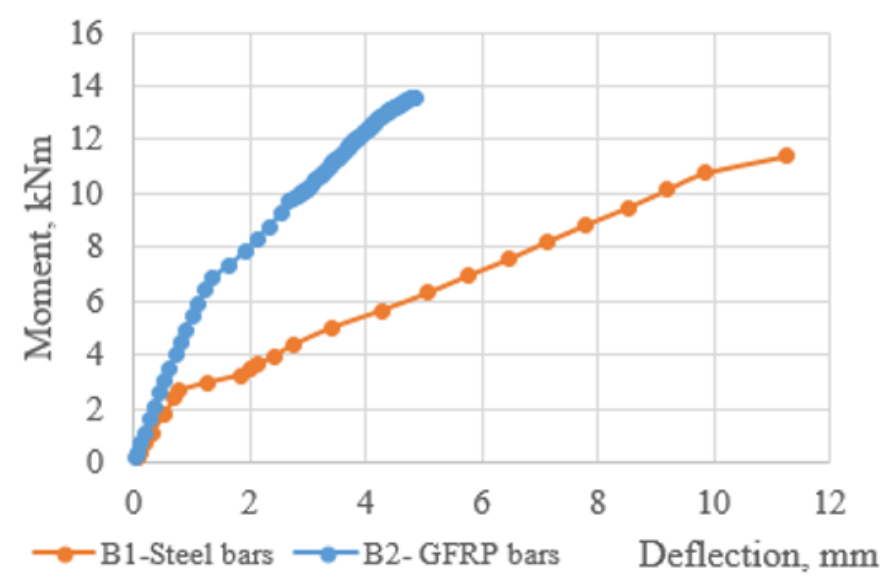

Fig. 7. Moment-deflection curve for B1\& B2.

Three-layer reinforced concrete beams using GFRP bars increase their cracking resistance (in this case, ability resistance to cracking increase about two times). Using this type of structure for buildings that require resistance cracking brings significant results.

To consider the possibility of cracking for multi-layer reinforced concrete beams, the authors analyzed stresses and deformation of three-layer beams while changing the thickness of the external (H1) and internal $(\mathrm{H} 2)$ layer of model beam B2 $(\mathrm{H} 1=50 \mathrm{~mm} \&$ $\mathrm{H} 2=150 \mathrm{~mm}$ ) for cases $\mathrm{H} 1=40 \mathrm{~mm} \& \mathrm{H} 2=170 \mathrm{~mm}(\mathrm{~B} 3)$; $\mathrm{H} 1=60 \mathrm{~mm} \& \mathrm{H} 2=130 \mathrm{~mm}$ (B4). The analysis results are shown in figure 8.

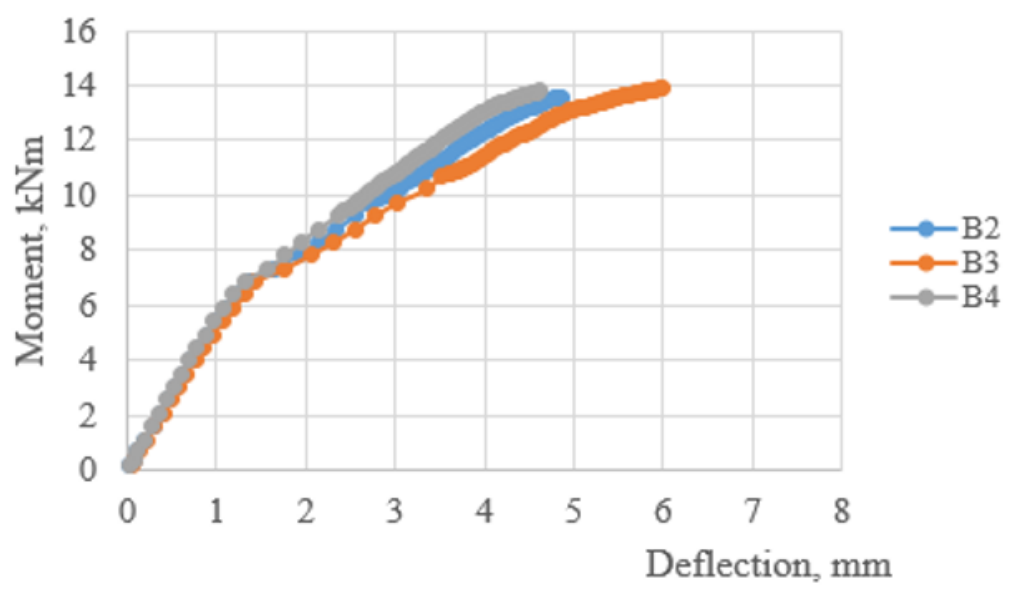

Fig. 8. Moment-deflection curve while changing the external layer thickness and the internal layer of the beam.

A common feature while analyzing samples B2, B3 \& B4 beams is that the internal layer modulus is much smaller than the elastic modulus of the external layer, so when applying GFRP bar composite fibers, the first cracks appear in the class internal concrete of the beam in the shear area of the beam. The moment forming the first crack of the beam (the internal layer of the beam) is not significantly different between cases. 


\section{Conclusion}

1. The use of the finite element (ANSYS PC) to analyze the stress state and deformation of $3 \mathrm{~L}-\mathrm{RC}$ structure including central layer from low thermal conductivity components is a contemporary and highly reliable method.

2. Three-layer RC beams applying composite bars are higher resistant to cracking than steel bars (in this circumstance, approximately 200\%).

3. The appliance of GFRP bars adjusts the stress - deformation state of multi-layer RC beams with the central layer using LWC. Cracks might appear within the layer of the beam, alternatively appearing in the outward layer as multi-layer RC beams with steel bars.

\section{References}

1. E.A. Korol, Three-layer enclosing reinforced concrete structures made of lightweight concrete and features of their calculation (Asv, Moc, 2001)

2. I. Bujnak, E.A. Korol, V.E. Latushkin, Communication, 1, 101 (2012)

3. E.A. Korol, Y.A. Kharkin, Vestnik MSSU, 3, 156-163 (2010)

4. V. D. Tho, E.A. Korol, N. H. Hoang, MATEC Web of Conferences 251, 04026 (2018)

5. E.A. Korol, V. D. Tho, N. H. Hoang, MATEC Web Conf, 196, 02022 (2018)

6. E.A. Korol, E.M. Pugach, A. Kharkin, Vestnik MSSU, 3, 67 (2014)

7. E.A. Korol, NSUACE, 5, 11 (2004)

8. SP 63-13330-2012, Concrete and reinforced concrete structures (Standard, Rus, 2012)

9. ГOCT P 51263-2012, Polystyrene. Technical conditions (Standard, Rus, 2012)

10. E.A. Korol, LOAF, 2, 5 (2000)

11. J. Bujnak, E.A. Korol, V.E. Latushkin, Communication, 1, 101 (2012)

12. L. K. Al-Hadithy, M. A. J. Hassan, NUCEJ, Vol 19, No. 2, 228 (2016)

13. P. Parandaman, M. Jayaraman, Middle-East Journal of Scientific Research, 22, 948 (2014)

14. S.D. Vanjara, J.M. Dave, IJAPME, Vol. 1, 4, 46 (2015)

15. J. Premalatha, R. Shanthi Vengadeshwari, IJCIET, Vol 8, 9, 671 (2017)

16. N. T. Dung, N. V. Moi, H. P. Hoa, Journal of Science and Technology, No. 3. p44. (Vietnam, 2011)

17. E Korol, VD Tho, Y Kustikova, IOP Conference Series, 365 (5), 052033 (2018)

18. A. J. Wolanski, Flexural Behaviour of Reinforced and Prestressed Concrete Beam using Finite Element Analysis (M.Sc. Thesis, Marquette University, 2004)

19. J.G. MacGregor, Reinforced Concrete Mechanics and Design (Prentice-Hall, Inc. Englewood Cliffs, 1992)

20. S. Moaveni, Finite element analysis: Theory and application with ANSYS, (London, 2015) 